\title{
SÍNDROME DE BURNOUT EM PROFESSORES NO BRASIL: CONSIDERAÇÕES PARA UMA AGENDA DE PESQUISA
}

\author{
BURNOUT SYNDROME IN TEACHERS IN BRAZIL: CONSIDERATIONS FOR A RESEARCH \\ AGENDA \\ SÍNDROME DE BURNOUT EN PROFESORES EN BRASIL: CONSIDERACIONES PARA UNA \\ AGENDA DE INVESTIGACIÓN
}

\author{
Larissa Dalcin* \\ Mary Sandra Carlotto*
}

\begin{abstract}
RESUMO
O estudo objetivou levantar e sumariar os principais resultados de pesquisas realizadas no tocante aos fatores associados à síndrome de burnout em professores no Brasil. A busca ocorreu nas bases de dados BVS, Scielo, Pepsic e PubMed e foram selecionados 16 artigos para compor a amostra final. Os resultados identificaram associação com variáveis individuais sociodemográficas e de personalidade, contextuais relacionadas ao cargo/ trabalho e consequências do burnout. Os resultados indicam que a produção do conhecimento ainda é incipiente e instável em termos de quantidade e é um tema investigado predominantemente pela Psicologia. $\mathrm{O}$ delineamento é, na sua totalidade, transversal e, em grande parte, utiliza o MBI como instrumento, amostras não probabilísticas e professores que lecionam em mais de um nível de ensino. Este estudo aponta para a necessidade de ampliação de uma agenda de pesquisas de burnout em professores, considerando as lacunas identificadas.
\end{abstract}

Palavras-chave: Síndrome de burnout. Professores. Revisão sistemática.

\begin{abstract}
This study aimed at raising and summarizing the main results of a systematic review of studies conducted regarding the associated factors to the burnout syndrome in teachers in Brazil. The search covered the BVS, Scielo, Pepsic, and PubMed databases. Sixteen articles were selected to compose the final sample of this study. The results identified associations with the individual socio-demographic and personality variables, job/work related contextual
\end{abstract}

\footnotetext{
Texto recebido em $1^{\circ}$ de dezembro de 2015 e aprovado para publicação em 25 de abril de 2016.

Doutoranda em Educação nas Ciências na Universidade Regional do Noroeste do Estado do Rio Grande do Sul (Unijuí); mestra em Psicologia Social pela Pontifícia Universidade Católica do Rio Grande do Sul (PUC-RS), psicóloga. E-mail: lddalcin@gmail. com.

** Doutora em Psicologia Social pela Universidade de Santiago de Compostela, Espanha; mestra em Saúde Coletiva pela Universidade Luterana do Brasil (Ulbra); psicóloga, docente do Programa de Pós-Graduação em Psicologia na Universidade do Vale do Rio dos Sinos (Unisinos). E-mail: mscarlotto@gmail.com.
} 
variables, and of burnout outcomes. The results indicate that the production of knowledge is still incipient and unstable in terms of quantity, being this subject mainly investigated by psychology. The majority of the studies were cross-sectional, and used the MBI tool with non-probabilistic samples, and with teachers teaching at more than one level of education. The present study points out to the need for an increase of the research agenda of the burnout in teachers, considering the identified limitations.

Keywords: Burnout syndrome. Teachers. Systematic review.

\section{RESUMEN}

El estudio pretendió obtener y resumir los principales resultados de investigaciones realizadas con respecto a factores asociados con el síndrome de burnout en profesores, en Brasil. La búsqueda se produjo en las bases de datos BVS, Scielo, Pepsic y PubMed y dieciséis artículos fueron seleccionados para componer la muestra final. Los resultados identificaron asociación con variables individuales sociodemográficas y de personalidad, contextuales relacionadas al cargo/trabajo y efectos del burnout. Los resultados indican que la producción de conocimientos es todavía incipiente e inestable en términos de cantidad y es un tema investigado de forma predominante por la psicología. La delineación es, en su totalidad, transversal y sobre todo usa el MBI como herramienta, muestras no probabilísticas y maestros que enseñan en más de un nivel de educación. Este estudio muestra la necesidad de ampliación de una agenda de investigaciones de burnout en profesores, teniendo en cuenta las deficiencias detectadas.

Palabras clave: Síndrome de Burnout. Profesores. Revisión sistemática.

\section{INTRODUÇÃO}

A síndrome de Burnout (SB) é caracterizada como uma reação à tensão emocional crônica, que tem acometido, principalmente, profissionais que desenvolvem seu trabalho atendendo pessoas de forma direta, constante e emocional (Leiter \& Maslach, 2014; Maslach \& Jackson, 1981; Maslach, Schaufeli, \& Leiter, 2001). É um tipo particular de mecanismo de enfrentamento e de autoproteção diante do estresse gerado entre profissional-cliente, assim como na relação profissional-organização (Gil-Monte, 2008). É, ainda, a consequência da relação precária entre os funcionários e seus respectivos locais de trabalho (Leiter \& Maslach, 2014).

A SB tem sido um dos tópicos mais investigados na área de Psicologia da Saúde Ocupacional (Bakker \& Costa, 2014), sendo avaliada como uma importante 
questão de saúde pública (Cebrià-Andreu, 2005; Gil-Monte, 2005; Palmer, Gomez-Vera, Cabrera-Pivaral, Prince-Vélez, \& Searcy, 2005) e destacada como um dos agravos ocupacionais de característica psicossocial mais importantes na atualidade (Salanova \& Llorens, 2008; Silva, Dias, \& Teixeira, 2012).

Entre as categorias profissionais, a de professores (Carlotto \& Câmara, 2008a; Droogenbroeck \& Spruyt, 2015) se destaca pela alta prevalência e pelas graves consequências ocasionadas, tais como provocar distúrbios patogênicos que prejudicam a saúde e a qualidade de vida do docente, afetando no processo ensinoaprendizagem. Para além desses fatores, cita-se ainda a sobrecarga de encargos financeiros sobre o orçamento público devido à rotatividade e absenteísmo de professores (Naghieh, Montgomery, Bonell, Thompson, \& Aber, 2015).

Diversos são os estressores ocupacionais relacionados ao trabalho docente, entre estes, podem-se citar as salas de aulas cada vez mais superlotadas, a pouca valorização profissional, a indisciplina dos alunos, as más condições de trabalho, a violência nas escolas, o acúmulo de funções sociais, o aumento da carga horária, as expectativas familiares e a falta de participação nas decisões institucionais (Bertaci, Santos, Coelho, \& Suda, 2011; Carlotto \& Palazzo, 2006; Silva, Silva, \& Martini, 2013).

Carlotto $(2010,2012)$ vem buscando identificar a existência de fatores associados à SB em professores. A autora destaca que Maslach, Schaufeli, e Leiter (2001) categorizam esses fatores em dois grupos de variáveis. São eles:

a) fatores individuais, que compreendem as variáveis sociodemográficas como sexo, idade, estado civil, situação conjugal, escolaridade, formação, remuneração e fatores de personalidade que abarcam suas características, as estratégias de enfrentamento (coping), a autoeficácia, o locus de controle, a autoestima, a motivação e a empatia;

b) fatores contextuais relacionados ao cargo/trabalho em que se consideram carga de trabalho, pressão do tempo, quantidade de alunos e horas trabalhadas, realização de atividades administrativas, relações interpessoais entre gestores, colegas, alunos e funcionários e familiares, condições físicas e recursos disponíveis, apoio social recebido, autonomia, demandas emocionais, satisfação, normas de funcionamento, valores organizacionais, modelo de gestão, políticas educacionais, questôes pedagógicas e de gestão curricular, cultura da escola, além de aspectos sociais, econômicos e culturais (Boa \& Deps, 2015; Maslach, Schaufeli, \& Leiter, 2001; Nogueira, 2012). 
No Brasil, desde a primeira publicação sobre a síndrome, em 1987, A sindrome de burnout, pelo médico Hudson, Hübner, e França (1987), importantes avanços nos estudos sobre a SB têm sido identificados (Carlotto \& Câmara, 2008a). Destacam-se duas revisóes nacionais realizadas especificamente sobre burnout em professores (Carlotto, 2010; Santos \& Nascimento Sobrinho, 2011).

$\mathrm{Na}$ revisão sistemática realizada por Carlotto (2010), apontava-se que, apesar de ter tido crescimento nas publicações, ainda havia certa instabilidade. Quanto aos fatores que se associavam à $\mathrm{SB}$, foi identificado um perfil constituído de professores mais jovens, do sexo feminino, com maior carga horária e maior número de alunos contatados diariamente, com menores satisfação com o trabalho e reconhecimento dos resultados obtidos neste.

Em revisão mais recente, realizada por Santos e Nascimento Sobrinho (2012), os resultados identificaram associação entre burnout e características do trabalho docente como o excesso de trabalho, a indisciplina dos alunos, a baixa remuneração, a falta de reconhecimento profissional e de reciprocidade na relação com os alunos, o conflito relativo à sobrecarga de papel, a relação professor-família, a presença de dúvidas quanto à competência profissional, problemas de relacionamento com colegas, formação insuficiente para a prática do trabalho e o excesso de responsabilidades.

Nas últimas décadas, o grande volume das informações científicas geradas na área da saúde aponta para a necessidade de sínteses que facilitem o acesso àquelas (Cordeiro, Oliveira, Rentería, \& Guimarães, 2007; Galvão \& Pereira, 2014). Tais sínteses, denominadas de revisão bibliográfica sistemática, avaliam estudos primários que contêm objetivos e materiais e métodos claramente explicitados, devendo ser conduzidas de acordo com uma metodologia clara e reprodutível (Greenhalgh, 1997; Sampaio \& Mancini, 2007).

A revisão sistemática pode ser útil para subsidiar novos estudos e intervenções a partir da identificação das lacunas do conhecimento. Nesse sentido, este estudo objetivou levantar e sumariar os principais resultados de pesquisas realizadas no tocante aos fatores associados ao burnout em professores, no Brasil.

\section{MÉTODO}

Para alcançar os objetivos deste estudo, realizou-se uma revisão sistemática por meio da busca eletrônica de artigos indexados nas seguintes bases: Scientific Electronic Library Online (Scielo Brasil), Biblioteca Virtual em Saúde (BVS) Periódicos Eletrônicos em Psicologia (Pepsic) e National Center for Biotechnology Information, U.S. National Library of Medicine (PubMed), com base nas 
palavras-chave: "professores" AND "burnout" e "teachers" AND "burnout" que constam como descritores no Descritores em Ciências da Saúde (DECs) e Biblioteca Virtual em Saúde Psicologia (BVS-PSI). Este estudo seguiu os padrões estabelecidos pelo Preferred Reporting Items for Systematic Reviews and MetaAnalysis (PRISMA), o qual serve de auxílio para os autores, a fim de melhorar a comunicação das revisões sistemáticas (Moher, Liberati, Tetzlaff, Altman, \& Prisma Group, 2010).

As bases foram selecionadas de acordo com os critérios de qualidade, abrangência e acessibilidade. A busca foi realizada em 29 de junho de 2015, sendo efetivada por três juízes-pesquisadores independentes e conhecedores da temática. Não foi estabelecido corte no período por motivo de ampliar a acessibilidade ao material já produzido pelo tema, indo ao encontro dos objetivos explicitados.

Ao final do levantamento baseado nas referências de artigos que estavam relacionados ao tema, optou-se por acrescentar uma pesquisa reversa manual, isto é, as referências dos artigos selecionados tornaram-se novas fontes de identificação de novos artigos (Costa \& Zoltowski, 2014). Segundo Pocinho (2008), esse tipo de busca, apesar de não ser obrigatória em revisões sistemáticas, serve de auxílio ao pesquisador, tornando-se muito importante no momento em que se identificam novos artigos não indexados nas bases pesquisadas, mas que são relevantes para a pesquisa realizada, tornando-a ainda mais completa.

Na primeira busca, foram identificados 410 artigos. Destes, foram excluídos 79 artigos, que se repetiram entre as bases. Em seguida, foram adotados os seguintes critérios de inclusão para a seleção dos artigos analisados nesta revisão:

a) artigos publicados com amostras nacionais de professores de escolas;

b) artigos de método quantitativo;

c) artigos com objetivo de identificar os fatores associados à SB em professores. Portanto, após essa análise, foram excluídos mais 318 artigos por não estarem de acordo com os critérios de inclusão. Ainda foram adicionados à amostra três artigos encontrados por meio de busca manual. Ao fim, a amostra compôs-se de 16 artigos. A figura 1 ilustra a sistemática de busca e seleção dos artigos. 
Figura 1. Fluxograma do processo de seleção e análise

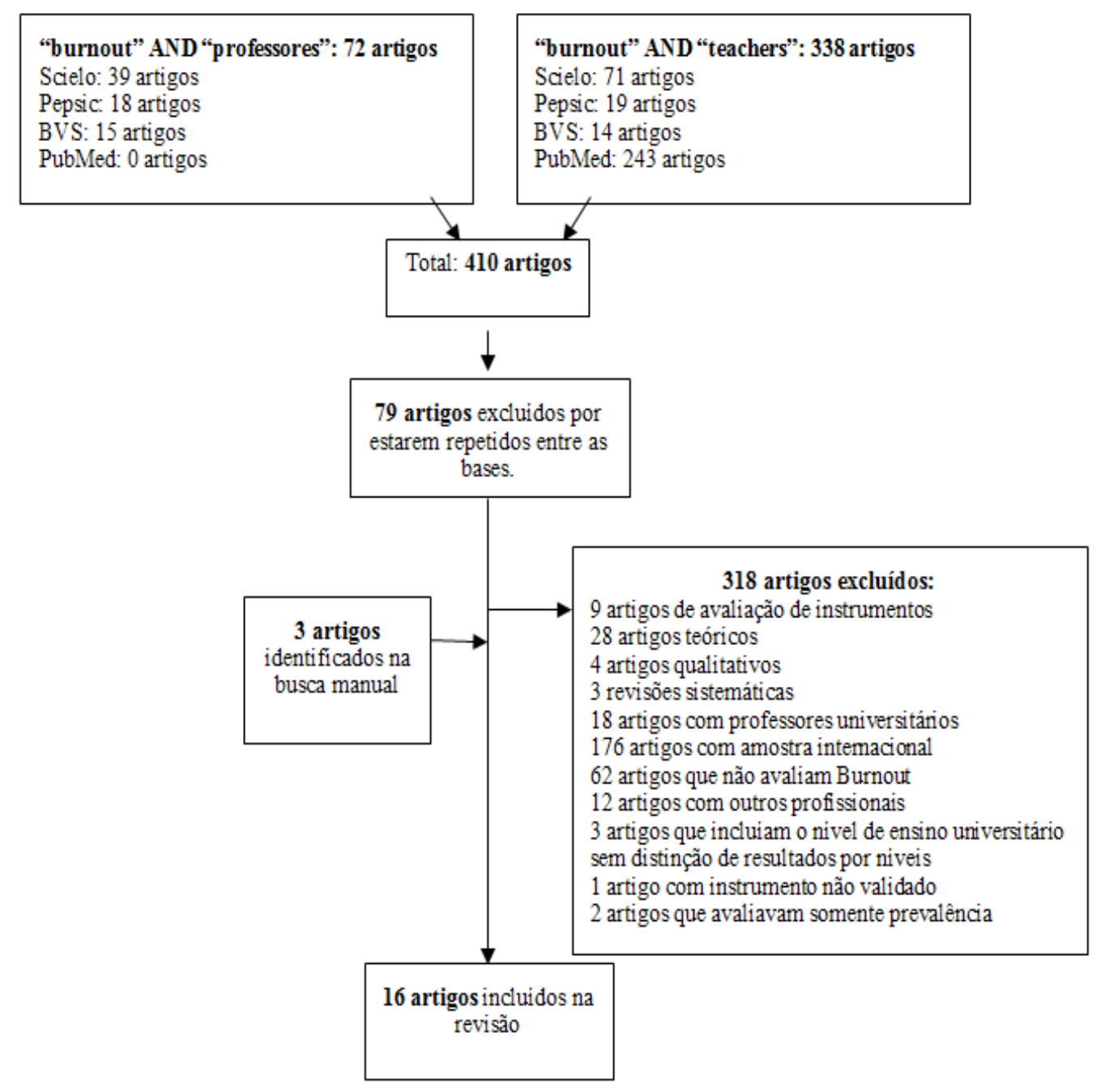

Fonte: elaborado pelas autoras.

Para fins de análise, os 16 artigos foram recuperados na íntegra. Com base nesse material e na realização da leitura de cada artigo, as informações foram organizadas de acordo com as seguintes categorias:

a) autor e ano do estudo;

b) objetivo do estudo;

c) área do conhecimento;

d) instrumento para avaliar burnout;

e) número de participantes, tipo de amostra e delineamento;

f) principais resultados (fatores associados). 


\section{RESULTADOS E DISCUSSÃO}

A apresentação dos resultados está organizada em duas seções. Na primeira, faz-se uma análise geral das características das publicações e, na segunda, são expostos os resultados referentes às variáveis associadas de acordo com os dois grupos de variáveis, individuais e características relacionadas ao cargo/trabalho. Um terceiro grupo foi incluído, denominado de consequências de burnout.

\subsection{Características gerais das publicações}

A partir dos dados obtidos dos artigos selecionados, pôde-se observar a instabilidade ainda existente quanto aos anos de publicação dos estudos, indicando que a SB em professores ainda é uma temática de estudo em consolidação no Brasil. A figura 2 indica o número de artigos publicados de acordo com os anos.

Figura 2. Número de artigos publicados por ano

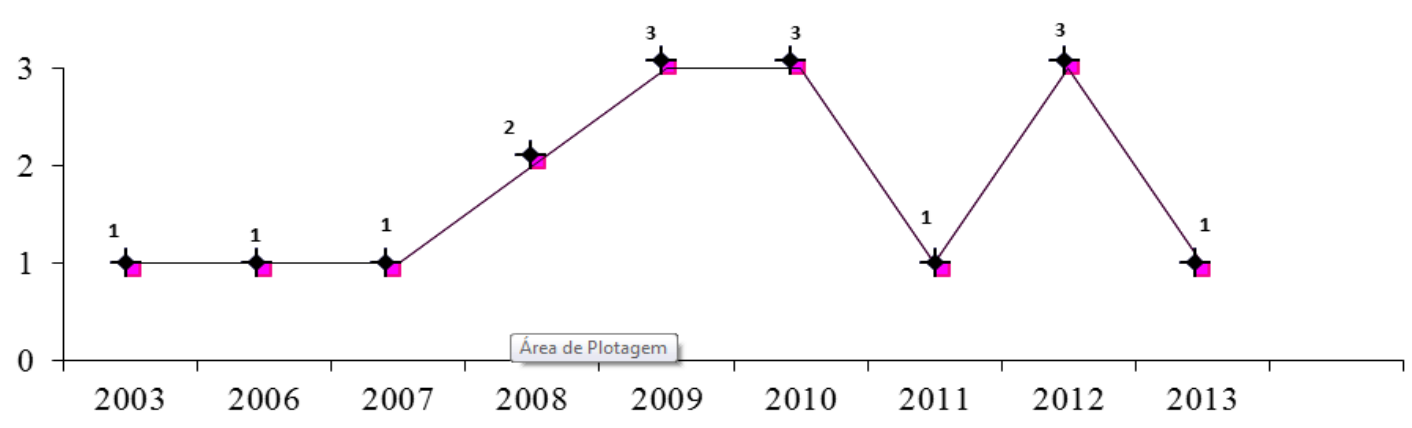

Fonte: elaborado pelas autoras.

Os resultados apontam que a síndrome de burnout em profissionais da educação vem recebendo atenção cada vez maior por parte dos pesquisadores (Andrade, 2012; Silva \& Carlotto, 2003), porém, apesar dos avanços teóricos sobre as relações entre trabalho e saúde dos docentes, no Brasil, a produção científica ainda se apresenta incipiente (Gomes, 2015) e instável.

A área de maior concentração dos autores dos estudos é a Psicologia $(\mathrm{n}=13 ; 81,25 \%)$, mas também áreas como a Psiquiatria, Saúde Coletiva, Nutrição, Engenharia da Produção, Educação, Matemática, Pedagogia e Saúde Ocupacional têm se voltado para essa temática, todavia com um menor número de publicações, apenas uma cada, o que indica ser um tema, igualmente, de interesse multidisciplinar. $O$ fato de a maior parte das publicações estar 
concentrada na área da Psicologia pode ser explicado pela síndrome de burnout ser considerada um fenômeno psicossocial (Maslach et al., 2001).

É possível verificar que o instrumento mais utilizado ( $\mathrm{n}=14 ; 87,5 \%)$ para avaliar a SB nos textos selecionados foi o Maslach Burnout Inventory (MBI), desenvolvido por Maslach e Jackson (1981), confirmando a literatura que tem referido que, independentemente das características ocupacionais da amostra ou de sua origem, o MBI é o instrumento mais utilizado para avaliar o burnout (Figueiredo-Ferraz, Gil-Monte, Queirós, \& Passos; 2014). Esse avalia burnout com base em três dimensōes, ou seja, exaustão emocional, despersonalização e baixa realização profissional (Maslach \& Jackson, 1981). O outro instrumento utilizado para avaliar a SB foi o Cuestionario para la Evaluación del Sindrome de Quemarse por el Trabajo (CESQT) $(\mathrm{n}=2 ; 12,5 \%)$ desenvolvido por Pedro GilMonte (2005), adaptado e validado para o uso em nosso país somente em 2010 (Gil-Monte, Carlotto, \& Câmara, 2010).

Apesar de o MBI ter obtido valores adequados de fidedignidade e validade (Gil-Monte, 2005), foi possível observar que também se detecta com frequência insuficiências psicométricas (Kristensen, Borritz, Villadsen, \& Christensen, 2005), principalmente quando o instrumento original é adaptado para outros idiomas que não o inglês (Garcia-Olmedo et al., 2001; Peeters \& Ruttel 2005; Truchot, Keirsebilck, \& Meyer, 2000). Para suprir essas dificuldades psicométricas, foi construído o CESQT, que apresenta similaridades com o MBI e constitui-se de quatro dimensões: ilusão pelo trabalho, desgaste psíquico, indolência e culpa (Gil-Monte, Carlotto, \& Câmara, 2010).

O CESQT pode facilitar o diagnóstico de indivíduos que venham a desenvolver a SB em diferentes culturas, superando, assim, as insuficiências de outros instrumentos (Gil-Monte et al., 2010; Gil-Monte, 2011).

Quanto aos níveis de ensino investigados, verificou-se que a maioria dos trabalhos publicados $(\mathrm{n}=9 ; 56,25 \%)$ utilizou amostra de professores que lecionam em mais de um nível (fundamental e médio). Nos estudos que analisam somente um nível de atuação, identificaram-se o ensino fundamental $(\mathrm{n}=2 ; 12,5 \%)$, o ensino especial $(n=2 ; 12,5 \%)$, o ensino médio $(n=1 ; 6,25 \%)$ e o pré-escolar $(\mathrm{n}=1 ; 6,25 \%)$. Também foi identificado estudo que contemplou diferenças entre os níveis fundamental, médio e universitário $(n=1 ; 6,25 \%)$. O predomínio de estudos sem diferenciar o nível de ensino é um aspecto que merece reflexão, pois há peculiaridades específicas nas atribuiçôes em cada nível (Byrne, 1991; Carlotto, 2005; Guglielmi \& Tatrow, 1998), que devem ser contempladas quando se estuda essa categoria profissional. 
O delineamento utilizado em todos os artigos foi o transversal, indo em sentido contrário às recomendaçôes de Gondim, Borges-Andrade, e Bastos (2010), que sugerem a realização de estudos longitudinais em razão da lacuna existente, tanto no Brasil quanto no exterior, desse tipo de estudo. No entanto, Taris e Kompier (2014) destacam que, especificamente no campo da Psicologia da Saúde Ocupacional, tem ocorrido um crescimento importante de estudos com esse delineamento, constituindo-se em um importante avanço.

Com relação às amostras, essas variam de 34 a 881 participantes e são, na sua maioria (75\%), não probabilísticas. Esse resultado pode revelar uma preocupação característica da fase inicial dos estudos de burnout que buscavam identificar relaçôes entre variáveis associadas ao constructo, mais do que com a possibilidade de generalização de seus resultados. Conquanto estudos epidemiológicos sejam importantes para a Psicologia, pois fornecem parâmetros para a interpretação de dados, especialmente no que diz respeito à prevenção e promoção da saúde (Kahhale, 2003), ainda são mais presentes na área da Medicina, cujo objetivo é identificar quadros psicopatológicos relacionados a determinadas categorias profissionais (Silva \& Merlo, 2007).

Essa é uma lacuna evidente nos estudos da temática, em que Leiter e Maslach (2014), Shaufeli, Malasch, e Marek (1993), enfatizam a importância de estudos epidemiológicos, com amostras probabilísticas, para que seja realizado um mapeamento mais detalhado da síndrome, com isso visando ao planejamento de ações de prevenção e possibilidades de intervenção em saúde do trabalhador a partir de possibilidades de generalização de seus resultados (Schaufeli et al., 1993).

\subsection{Fatores associados à síndrome de burnout}

\subsubsection{Variáveis individuais}

Os resultados relacionados às variáveis sociodemográficas que utilizaram o modelo de três dimensões de burnout revelam que a exaustão emocional é maior em mulheres, professores sem filhos, com união estável e diminui de acordo com a elevação da idade. A despersonalização encontra-se maior em homens, profissionais que não têm união estável, sem filhos; eleva-se com o aumento da idade e associa-se à faixa etária de 40 a 59 anos. A realização profissional é maior em mulheres, profissionais com filhos, que não têm companheiro fixo e diminui de acordo com o aumento da idade. No modelo de quatro fatores, verificou-se que ter filhos é um fator que diminui a indolência, e a dimensão de culpa está associada às variáveis sexo feminino e ter filhos. 
Embora esse grupo de variáveis seja um dos mais investigados na literatura de burnout (Cabrera \& Elvira, 2004; Santos e Nascimento Sobrinho, 2011), revisão sistemática realizada por Carlotto e Câmara (2008a) identificou que ainda não havia consolidação dos resultados em relação a tais variáveis no Brasil. Os resultados obtidos revelam que ainda é incipiente o conhecimento sobre a relação entre variáveis sociodemográficas e burnout em professores, visto que variáveis como renda e formação do profissional não são identificadas e, portanto, merecem maior atenção por parte dos pesquisadores.

Nos estudos que relacionam burnout a variáveis de personalidade, verifica-se a utilização do constructo estratégias de enfrentamento. Esse revela que o aumento da exaustão emocional está associado a maior utilização de coping moderado, foco na emoção e desligamento mental. A despersonalização se apresenta maior em relação ao menor suporte emocional e diminui associada a maior coping ativo. $\mathrm{O}$ aumento da realização profissional associa-se a maior coping ativo, suporte emocional e reinterpretação positiva. Esse mesmo constructo--utilizado em outras dimensões, mostrou que, em professores de escolas públicas, a exaustão emocional aumenta com a maior utilização das estratégias de afastamento, fuga e esquiva, assim como a despersonalização aumenta com o uso de estratégia de afastamento. A realização profissional diminui com o uso de maior estratégia de afastamento e aumenta com uso de estratégias de solução de problemas. Já nas escolas privadas, a exaustão emocional e a despersonalização aumentam conforme haja maior utilização de estratégias de afastamento. A realização profissional diminui com o maior uso da estratégia de aceitação de responsabilidade.

No modelo de quatro dimensões, a ilusão pelo trabalho aumenta em relação à maior utilização de estratégias de controle e diminui em relação ao uso de estratégias de esquiva. $\mathrm{O}$ desgaste psíquico e a indolência aumentam quando associados ao uso de estratégias de esquiva. $\mathrm{Na}$ avaliação da relação com a autoeficácia, verificou-se associação positiva com ilusão pelo trabalho e negativa com o desgaste psíquico e indolência.

As variáveis de personalidade como estratégias de enfrentamento e autoeficácia são as que apresentam maior defasagem nos estudos nacionais identificados, quando comparados aos internacionais no que diz respeito a estabelecer um perfil de personalidade para burnout. Há uma vasta literatura internacional que investiga a associação de burnout a esses dois constructos (Aftab, Shah, \& Mehmood, 2012; Fernet, Austin, Trépanier, \& Dussault, 2013; García-Renedo, Llorens, Cifre, \& Salanova, 2006). No entanto, observa-se que muitas outras variáveis em nível individual podem desempenhar papel relevante na mediação entre sobrecarga e burnout, por exemplo, variáveis de personalidade e estratégias de coping (Carlotto, Dias, Batista, \& Diehl, 2015). Portanto se percebe a 
importância de maior ampliação de estudos com essas variáveis, bem como de estudos que avaliem locus de controle e características+ de personalidade.

\subsubsection{Variáveis contextuais relacionadas ao cargo/trabalho}

Os resultados relacionados às variáveis contextuais que utilizaram o modelo de três dimensões de burnout revelaram que a exaustão emocional aumenta conforme aumenta a percepção de que a profissão é estressante, as expectativas familiares são um fator de estresse, acreditar que a profissão está interferindo na vida pessoal, considerar a profissão menos interessante de quando começou. E ainda, à proporção que se trabalha com um número maior de alunos, de horas trabalhadas, de tempo de docência e de atuação em escola pública, encontramse menor satisfação com crescimento profissional, menor potencial motivacional do cargo, menor condiçôes de trabalho, estabilidade, constitucionalismo na organização do trabalho, avaliação geral da qualidade de vida no trabalho e ruídos no ambiente. Por outro lado, a exaustão diminui quando associada a maior satisfação com colegas, trabalho e salário.

A despersonalização aumenta com maior tempo de serviço, percepção das expectativas familiares, mau comportamento dos alunos, falta de participação nas decisões institucionais considerada como fator de estresse, de oportunidade futura de crescimento, de estabilidade e trabalho como espaço total de vida, de estabilidade no emprego, de atuar em escola pública, de menor satisfação com o crescimento profissional, de maior variedade de habilidades, de melhor situação funcional. No entanto essa dimensão tende a diminuir com maior satisfação intrínseca com a tarefa, mais contato social, melhor relação com colegas e alunos.

A realização profissional diminui conforme o maior tempo de exercício profissional, pensamento de mudar de profissão, percepção de mau comportamento dos alunos como estressor, acreditar que o trabalho interfere na vida pessoal, considerar a profissão menos interessante do que quando começou, acreditar que a profissão está gerando estresse, atuar em escola pública, maior carga horária e número de alunos, menor satisfação com crescimento e contato social e estabilidade no trabalho; no entanto aumenta com maior satisfação no trabalho, melhor relacionamento com colegas e alunos, oportunidade futura de crescimento, segurança e trabalho como espaço total de vida.

No modelo de quatro dimensões de burnout, a ilusão pelo trabalho aumenta com maior autonomia, apoio social, feedback positivo e satisfação no trabalho, mas essa dimensão diminui quando associada a maior conflito e ambiguidade de papel, iniquidade e sobrecarga de trabalho. $\mathrm{O}$ desgaste psíquico aumenta com maior conflito e ambiguidade de papel, sobrecarga de trabalho e diminui com 
maior autonomia, apoio social, feedback positivo e satisfação com o trabalho. A dimensão indolência aumenta quando associada a menor autonomia e apoio social. O sentimento de culpa aumenta com maior conflito e ambiguidade de papel, sobrecarga de trabalho e maior número de alunos atendidos.

A análise desse conjunto de variáveis indica a investigação focalizada em estressores, características do cargo e satisfação no trabalho. Embora sejam variáveis que têm demonstrado sua importância nos modelos explicativos de burnout, verifica-se a necessidade de ampliação, a fim de dar maior consistência aos resultados das investigaçôes, pois, segundo o modelo teórico de burnout de Maslach, nas características do trabalho é que residem suas maiores causas (Maslach \& Leiter, 1997). Para além do estudo da presença de demandas de trabalho, as pesquisas devem direcionar-se para a investigação de variáveis como a falta de recursos físicos e materiais ao trabalho. Nessa categoria, pôdese verificar que existe um número maior de possibilidades a ser avaliado. Com base nesses dados, perceberam-se opções de maior diversificação de resultados, podendo também apresentar como variáveis de futuros estudos, além das já citadas neste artigo, a preparação insuficiente dos profissionais para a prática do trabalho, o excesso de responsabilidades, a diferença entre os níveis de ensino, a violência que está cada dia mais presente nas escolas, o tempo e a qualidade de deslocamento dos profissionais de casa para o trabalho e vice-versa, além de pesquisas que visem ao ambiente físico escolar, bem como a cultura e as normas da instituição.

\subsubsection{Consequências de burnout}

No modelo de três dimensões, a exaustão emocional apresentou-se com maiores níveis quando relacionada ao afastamento do emprego por problemas de saúde e à frequência de pensar em mudar de profissão; e a realização profissional evidenciou-se mais elevada quando associada ao pensamento de mudar de profissão. Já no modelo de quatro dimensões apresentado por Gil-Monte (2005), verificou-se que a ilusão pelo trabalho diminui conforme se apresenta relacionada com problemas de saúde.

Revelou-se que o componente de exaustão em burnout é o mais preditivo de resultados que relacionem saúde e estresse, principalmente em forma de doença mental (Maslach et al., 2001). Os autores ainda revelam que indivíduos mentalmente saudáveis têm mais capacidade de lidar com o estresse crônico e, portanto, são menos propensos a desenvolver burnout. Segundo Gasparini, Barreto, e Assunção (2005), é possível observar a prevalência de afastamento de professores, visto que os transtornos psíquicos são os responsáveis pela maioria dos casos. 
O nível de saúde das pessoas pode ser afetado por diversos fatores, incluindo o estresse (Suda, Coelho, Bertaci, \& Santos, 2011), sintoma característico da SB. Assim, pode-se inferir, com base nos referenciais citados neste texto, que a SB implica em comprometimento da saúde física e mental do trabalhador, com impactos patogênicos em sua qualidade de vida no trabalho (Batista, Carlotto, Coutinho, \& Augusto, 2010). Portanto, a variável estresse merece maior atenção por parte dos pesquisadores, que realizam estudos sobre a relação burnout, qualidade de vida, qualidade de vida no trabalho, bem como aqueles voltados aos transtornos mentais comuns, depressão, transtornos do comportamento relacionados ao trabalho e adição ao trabalho.

\section{CONCLUSÃO}

A análise da produção científica brasileira sobre os fatores associados ao burnout em professores permitiu resumir as evidências quanto ao tema e mapear as lacunas que podem ser preenchidas por novos estudos. Os estudos revelam um perfil constituído por mulheres, profissionais mais jovens, que têm filhos, companheiro fixo e que, geralmente, fazem uso de estratégias de enfrentamento focalizadas na emoção ou evitação. Os docentes que atendem um número maior de alunos diariamente, têm maior carga horária e sobrecarga de trabalho, mais tempo de docência, atuam em escola pública, têm estabilidade no emprego, sob piores condições de trabalho, convivendo com ruídos no ambiente, constitucionalismo na organização do trabalho, convivem com conflito, ambiguidade de papel e iniquidade, variedade de habilidades, com cargos de chefia, com situação funcional mais autônoma constituem-se como a população mais propensa ao burnout.

De modo geral, os profissionais percebem a profissão, as expectativas familiares, o mau comportamento dos alunos e a falta de participação nas decisões institucionais como estressantes. Acreditam que a profissão está interferindo como fator estressor na vida pessoal, consideram a profissão menos interessante de quando iniciou e, na avaliação sobre qualidade de vida no trabalho, consideram o trabalho como espaço total de vida.

Como consequências do burnout, verificaram-se docentes que se afastaram do emprego por problemas de saúde, pensam em mudar de profissão e apresentam algum problema de saúde. No entanto se evidenciou, conforme os resultados, um perfil de profissionais menos propenso ao desenvolvimento da $\mathrm{SB}$, isto é, o que tem melhor relação com colegas e alunos, mais apoio social, facilidade no contato social, potencial motivacional do cargo, oportunidade futura de crescimento, satisfação com crescimento profissional, satisfação com colegas, 
trabalho e salário, satisfação intrínseca com a tarefa, feedback positivo e satisfação geral no trabalho.

Os resultados deste estudo revelam a necessidade de ampliação da agenda de pesquisa sobre a SB em professores. Sugere-se uma ampliação do conjunto de variáveis sociodemográficas, como renda e formação; a inclusão de fatores de personalidade, como autoestima, motivação e empatia; além de variáveis laborais, incluindo regime de trabalho e atividade em mais de uma instituição, o tempo e a qualidade do deslocamento dos profissionais de casa para o trabalho ou de um trabalho para outro, níveis de ensino, pressão do tempo, realização de atividades administrativas e demandas emocionais. Seria relevante, ainda, a realização de pesquisas que abordem a violência que vem sendo vivenciada no contexto escolar bem como a ampliação de pesquisas relacionadas ao ambiente físico escolar, à cultura, às normas e a relação entre gestores e profissionais.

Também são importantes investigações que incluam variáveis psicossociais, principalmente a interação trabalho-família, haja vista a importância dessa variável no contexto laboral atual. Aponta-se, ainda, a necessidade de incluir variáveis de saúde como transtornos mentais comuns, transtornos do comportamento relacionados ao trabalho, depressão e adição ao trabalho.

No tocante às características da produção, pôde-se verificar que, embora tenha ocorrido um discreto aumento de publicaçóes ao longo dos anos, os estudos científicos identificados ainda são escassos. A predominância de estudos transversais aponta uma carência de investigaçôes longitudinais, prospectivas e retrospectivas (Breakwell \& Rose, 2010; Davis \& Bremmer, 2010; Mota, 2010). Os estudos identificados na revisão são predominantemente com amostras não probabilísticas, o que limita a generalização e consolidação de seus resultados. 


\section{Quadro 1 - Descrição das publicações}

\begin{tabular}{|c|c|c|c|c|}
\hline Autor/Ano & Objetivo & Área dos autores & Instrumento & $\begin{array}{l}\text { Amostra/tipo } \\
\text { de amostra/ } \\
\text { delineamento }\end{array}$ \\
\hline $\begin{array}{l}\text { Silva \& Carlotto } \\
\text { (2003) }\end{array}$ & $\begin{array}{c}\text { Analisar se o gê- } \\
\text { nero estabelece } \\
\text { diferenças signifi- } \\
\text { cativas nos níveis } \\
\text { e no processo da } \\
\text { síndrome de bur- } \\
\text { nout. }\end{array}$ & Psicologia & $\mathrm{MBI}$ & $\begin{array}{l}\text { Ensinos fun- } \\
\text { damental e } \\
\text { médio } \\
\text { n= } 61 \text { /Não } \\
\text { probabilística } \\
\text { Estudo epi- } \\
\text { demiológico } \\
\text { transversal. }\end{array}$ \\
\hline $\begin{array}{l}\text { Carlotto \& Palaz- } \\
\quad \text { zo (2006) }\end{array}$ & $\begin{array}{l}\text { Avaliar a SB em } \\
\text { professores de } \\
\text { escolas particu- } \\
\text { lares e possíveis } \\
\text { associações com } \\
\text { variáveis demo- } \\
\text { gráficas, laborais } \\
\text { e fatores de es- } \\
\text { tresse percebidos } \\
\text { no trabalho. }\end{array}$ & $\begin{array}{l}\text { Psicologia e Psi- } \\
\text { quiatria }\end{array}$ & $\mathrm{MBI}$ & $\begin{array}{l}\text { Ensinos fun- } \\
\text { damental e } \\
\text { médio } n=217 \\
\text { Probabilística } \\
\text { Estudo epi- } \\
\text { demiológico } \\
\text { transversal. }\end{array}$ \\
\hline $\begin{array}{l}\text { Carlotto \& Câma- } \\
\quad \text { ra (2007) }\end{array}$ & $\begin{array}{l}\text { Identificar oS } \\
\text { preditores da SB } \\
\text { em professores } \\
\text { de instituições } \\
\text { particulares em } \\
\text { diferentes níveis } \\
\text { de ensino }\end{array}$ & Psicologia & $\mathrm{MBI}$ & $\begin{array}{l}\text { Ensinos funda- } \\
\text { mental, médio } \\
\text { e superior } \\
\text { n= } 563 \text { Não } \\
\text { probabilística } \\
\text { Estudo obser- } \\
\text { vacional analí- } \\
\text { tico transversal }\end{array}$ \\
\hline $\begin{array}{l}\text { Mazon, Carlotto } \\
\text { \& Câmara (2008) }\end{array}$ & $\begin{array}{l}\text { Identificar a exis- } \\
\text { tência de associa- } \\
\text { ção entre as di- } \\
\text { mensões de SB e } \\
\text { as estratégias de } \\
\text { enfrentamento. }\end{array}$ & Psicologia & $\mathrm{MBI}$ & $\begin{array}{l}\text { Ensino funda- } \\
\text { mental } \\
\mathrm{n}=356 \text { Proba- } \\
\text { bilística } \\
\text { Estudo obser- } \\
\text { vacional analí- } \\
\text { tico transversal }\end{array}$ \\
\hline $\begin{array}{l}\text { Carlotto \& Câma- } \\
\quad \text { ra (2008b) }\end{array}$ & $\begin{array}{l}\text { Identificar se } \\
\text { há diferença na } \\
\text { relação existente } \\
\text { entre estratégias } \\
\text { de enfrentamen- } \\
\text { to e SB em pro- } \\
\text { fessores de insti- } \\
\text { tuições públicas e } \\
\text { privadas. }\end{array}$ & Psicologia & $\mathrm{MBI}$ & $\begin{array}{l}\text { Ensinos fun- } \\
\text { damental e } \\
\text { médio } \\
\text { n= } 81 \text { Não } \\
\text { probabilística } \\
\text { Estudo obser- } \\
\text { vacional analí- } \\
\text { tico transversal }\end{array}$ \\
\hline
\end{tabular}




\begin{tabular}{|c|c|c|c|c|}
\hline $\begin{array}{c}\text { Tibúrcio \& More- } \\
\text { no (2009) }\end{array}$ & $\begin{array}{l}\text { Estimar a preva- } \\
\text { lência da SB em } \\
\text { professores de } \\
\text { escola pública } \\
\text { estadual. }\end{array}$ & Saúde Coletiva & $\mathrm{MBI}$ & $\begin{array}{c}\text { Ensino médio } \\
\mathrm{n}=101 \text { Não } \\
\text { probabilística } \\
\text { Estudo obser- } \\
\text { vacional trans- } \\
\text { versal }\end{array}$ \\
\hline $\begin{array}{l}\text { Lopes \& Pontes } \\
\text { (2009) }\end{array}$ & $\begin{array}{l}\text { Analisar se pro- } \\
\text { fessores da rede } \\
\text { pública e particu- } \\
\text { lar têm diferentes } \\
\text { dimensões de } \\
\text { burnout e se } \\
\text { variáveis demo- } \\
\text { gráficas, profis- } \\
\text { sionais e laborais } \\
\text { associam-se de } \\
\text { forma diferente } \\
\text { ao burnout. }\end{array}$ & $\begin{array}{l}\text { Psicologia e Ma- } \\
\text { temática }\end{array}$ & $\mathrm{MBI}$ & $\begin{array}{l}\text { Ensinos fun- } \\
\text { damental e } \\
\text { médio } \\
\text { n= } 40 \text { Não } \\
\text { probabilística } \\
\text { Estudo obser- } \\
\text { vacional analí- } \\
\text { tico transversal }\end{array}$ \\
\hline $\begin{array}{l}\text { Moreira, Farias, } \\
\text { Both \& Nasci- } \\
\text { mento (2012) }\end{array}$ & $\begin{array}{l}\text { Verificar a corre- } \\
\text { lação entre qua- } \\
\text { lidade de vida no } \\
\text { trabalho e SB em } \\
\text { professores de } \\
\text { Educação Física. }\end{array}$ & Pedagogia & $\mathrm{MBI}$ & $\begin{array}{l}\text { Ensinos fun- } \\
\text { damental e } \\
\text { médio } \\
\mathrm{n}=149 \text { Não } \\
\text { probabilística } \\
\text { Estudo descri- } \\
\text { tivo explorató- } \\
\text { rio transversal }\end{array}$ \\
\hline $\begin{array}{l}\text { Rodrigues, Cha- } \\
\text { ves \& Carlotto } \\
\text { (2010) }\end{array}$ & $\begin{array}{l}\text { Verificar a exis- } \\
\text { tência de asso- } \\
\text { ciação entre as } \\
\text { dimensões da SB } \\
\text { e variáveis demo- } \\
\text { gráficas, laborais } \\
\text { e psicossociais. }\end{array}$ & Psicologia & $\mathrm{MBI}$ & $\begin{array}{l}\text { Educação in- } \\
\quad \text { fantil } \\
n=34 \text { Não } \\
\text { probabilística } \\
\text { Estudo obser- } \\
\text { vacional analí- } \\
\text { tico transversal }\end{array}$ \\
\hline Carlotto (2010) & $\begin{array}{c}\text { Avaliar a relação } \\
\text { entre a SB, níveis } \\
\text { de ensino e variá- } \\
\text { veis laborais. }\end{array}$ & Psicologia & $\mathrm{MBI}$ & $\begin{array}{l}\begin{array}{c}\text { Ensinos fun- } \\
\text { damental e } \\
\text { médio }\end{array} \\
\begin{array}{c}\mathrm{n}= \\
171 \text { Proba- } \\
\text { bilística }\end{array} \\
\text { Estudo obser- } \\
\text { vacional analí- } \\
\text { tico transversal }\end{array}$ \\
\hline
\end{tabular}




\begin{tabular}{|c|c|c|c|c|}
\hline $\begin{array}{l}\text { Batista, Carlotto, } \\
\text { Coutinho \& Au- } \\
\text { gusto (2010) }\end{array}$ & $\begin{array}{l}\text { Avaliar a preva- } \\
\text { lência da SB nos } \\
\text { professores da } \\
\text { primeira fase } \\
\text { do Ensino Fun- } \\
\text { damental e sua } \\
\text { relação com as } \\
\text { variáveis socio- } \\
\text { demográficas e } \\
\text { laborais. }\end{array}$ & $\begin{array}{l}\text { Educação, Psico- } \\
\text { logia, Engenharia } \\
\text { de Produção }\end{array}$ & $\mathrm{MBI}$ & $\begin{array}{l}\text { Ensino funda- } \\
\text { mental }\end{array}$ \\
\hline Carlotto (2011) & $\begin{array}{l}\text { Identificar a pre- } \\
\text { valência da SB e } \\
\text { sua relação com } \\
\text { fatores socio- } \\
\text { demográficos e } \\
\text { laborais. }\end{array}$ & Psicologia & $\mathrm{MBI}$ & $\begin{array}{l}\text { Ensinos fun- } \\
\text { damental e } \\
\text { médio } \\
\text { n= } 881 \text { Não } \\
\text { probabilística } \\
\text { Estudo obser- } \\
\text { vacional analí- } \\
\text { tico transversal }\end{array}$ \\
\hline $\begin{array}{l}\text { Carlotto, Librelo- } \\
\text { tto, Pizzinato \& } \\
\text { Barcinski (2012) }\end{array}$ & $\begin{array}{l}\text { Identificar a pre- } \\
\text { valência da SB e } \\
\text { sua associação } \\
\text { com fatores de } \\
\text { risco psicossocial. }\end{array}$ & Psicologia & CESQT & $\begin{array}{l}\begin{array}{c}\text { Ensino espe- } \\
\text { cial }\end{array} \\
\text { n= } 63 \text { Não } \\
\text { probabilística } \\
\text { Estudo obser- } \\
\text { vacional analí- } \\
\text { tico transversal }\end{array}$ \\
\hline $\begin{array}{c}\text { Costa \& Silva } \\
(2011)\end{array}$ & $\begin{array}{l}\text { Analisar os fato- } \\
\text { res que afetam } \\
\text { o ambiente de } \\
\text { trabalho a quali- } \\
\text { dade de vida dos } \\
\text { professores. }\end{array}$ & $\begin{array}{l}\text { Saúde Ocupa- } \\
\text { cional }\end{array}$ & $\mathrm{MBI}$ & $\begin{array}{l}\text { Ensino fun- } \\
\text { damental e } \\
\text { médio } \\
\mathrm{n}=100 \text { Não } \\
\text { probabilística } \\
\text { Estudo obser- } \\
\text { vacional analí- } \\
\text { tico transversal }\end{array}$ \\
\hline
\end{tabular}




\begin{tabular}{|c|c|c|c|c|}
\hline $\begin{array}{c}\text { Santana, De Mar- } \\
\text { chi, Júnior, Giron- } \\
\text { doli \& Chiappeta } \\
\text { (2011) }\end{array}$ & $\begin{array}{l}\text { Avaliar a ocor- } \\
\text { rência de SB e a } \\
\text { correlação com } \\
\text { condições de } \\
\text { trabalho. }\end{array}$ & Nutrição & $\mathrm{MBI}$ & $\begin{array}{c}\text { Ensino fun- } \\
\text { damental e } \\
\text { médio } \\
\mathrm{n}=100 \text { Não } \\
\text { probabilística } \\
\text { Estudo obser- } \\
\text { vacional trans- } \\
\text { versal }\end{array}$ \\
\hline $\begin{array}{l}\text { Braun \& Carlotto } \\
\text { (2013) }\end{array}$ & $\begin{array}{l}\text { Verificar a preva- } \\
\text { lência de SB e a } \\
\text { relação com va- } \\
\text { riáveis e coping. }\end{array}$ & Psicologia & CESQT & $\begin{array}{l}\text { Ensino espe- } \\
\text { cial } \\
\text { n= } 88 \text { Não } \\
\text { probabilística } \\
\text { Estudo obser- } \\
\text { vacional analí- } \\
\text { tico transversal }\end{array}$ \\
\hline
\end{tabular}

Fonte: elaborado pelas autoras.

Tabela 1. Fatores associados às dimensões da síndrome e burnout

\begin{tabular}{|l|c|c|c|c|c|c|c|}
\hline Variáveis & \multicolumn{3}{|c|}{ MBI } & \multicolumn{5}{c|}{ CESQT } \\
\hline & EE & DE & RP & IL & DP & IN & CL \\
\hline Individuais (sociodemográficas) & & & & & & & \\
\hline Sexo feminino & + & 0 & + & 0 & 0 & 0 & + \\
\hline Sexo masculino & 0 & + & 0 & 0 & 0 & 0 & 0 \\
\hline Idade & - & + & - & 0 & 0 & 0 & 0 \\
\hline Ter filhos & + & - & + & 0 & 0 & - & + \\
\hline União estável & + & - & - & 0 & 0 & 0 & 0 \\
\hline Individuais (personalidade) & & & & & & & \\
\hline Coping focado no problema & 0 & - & + & + & 0 & 0 & 0 \\
\hline Coping focado na emoção & + & + & + & 0 & 0 & 0 & 0 \\
\hline Coping de evitação & + & + & - & - & + & + & 0 \\
\hline Autoeficácia & 0 & 0 & 0 & + & - & - & 0 \\
\hline Contextuais & & & & & & & \\
\hline $\begin{array}{l}\text { Quantidade de aluno atendida diaria- } \\
\text { mente }\end{array}$ & + & 0 & - & 0 & 0 & 0 & + \\
\hline Horas diárias de trabalho & + & 0 & - & 0 & 0 & 0 & 0 \\
\hline Tempo de docência & + & + & - & 0 & 0 & 0 & 0 \\
\hline Atuar em escola pública & + & + & - & 0 & 0 & 0 & 0 \\
\hline Mau comportamento dos alunos & 0 & + & - & 0 & 0 & 0 & 0 \\
\hline Melhor relação com colegas e alunos & 0 & - & + & 0 & 0 & 0 & 0 \\
\hline
\end{tabular}




\begin{tabular}{|c|c|c|c|c|c|c|c|}
\hline Sobrecarga de trabalho & 0 & 0 & 0 & - & + & 0 & + \\
\hline Apoio social & 0 & 0 & 0 & + & - & - & 0 \\
\hline Contato social & 0 & - & + & 0 & 0 & 0 & 0 \\
\hline Potencial motivacional do cargo & - & 0 & 0 & 0 & 0 & 0 & 0 \\
\hline Condições de trabalho & + & 0 & 0 & 0 & 0 & 0 & 0 \\
\hline $\begin{array}{l}\text { Constitucionalismo na organização do } \\
\text { trabalho }\end{array}$ & + & 0 & 0 & 0 & 0 & 0 & 0 \\
\hline Ruídos no ambiente & + & 0 & 0 & 0 & 0 & 0 & 0 \\
\hline $\begin{array}{l}\text { Falta de participação nas decisões insti- } \\
\text { tucionais }\end{array}$ & 0 & + & 0 & 0 & 0 & 0 & 0 \\
\hline Oportunidade futura de crescimento & 0 & + & + & 0 & 0 & 0 & 0 \\
\hline Estabilidade no emprego & + & + & - & 0 & 0 & 0 & 0 \\
\hline Variedade de habilidades & 0 & + & 0 & 0 & 0 & 0 & 0 \\
\hline Melhor situação funcional & 0 & + & 0 & 0 & 0 & 0 & 0 \\
\hline Autonomia & 0 & 0 & 0 & + & - & - & 0 \\
\hline Conflito e ambiguidade de papel & 0 & 0 & 0 & - & + & 0 & + \\
\hline Iniquidade & 0 & 0 & 0 & - & 0 & 0 & 0 \\
\hline Perceber a profissão como estressante & + & 0 & - & 0 & 0 & 0 & 0 \\
\hline $\begin{array}{l}\text { Perceber expectativas familiares como } \\
\text { estressantes }\end{array}$ & + & + & 0 & 0 & 0 & 0 & 0 \\
\hline $\begin{array}{l}\text { Acreditar que a profissão interfere na } \\
\text { vida pessoal }\end{array}$ & + & 0 & - & 0 & 0 & 0 & 0 \\
\hline $\begin{array}{l}\text { Profissão menos interessante de quanto } \\
\text { iniciou }\end{array}$ & + & 0 & - & 0 & 0 & 0 & 0 \\
\hline Satisfação com crescimento profissional & - & - & + & 0 & 0 & 0 & 0 \\
\hline $\begin{array}{l}\text { Avaliação geral da qualidade de vida no } \\
\text { trabalho }\end{array}$ & + & 0 & 0 & 0 & 0 & 0 & 0 \\
\hline $\begin{array}{l}\text { Satisfação com colegas, trabalho e salá- } \\
\text { rio }\end{array}$ & - & 0 & 0 & 0 & 0 & 0 & 0 \\
\hline Trabalho como espaço total de vida & 0 & + & + & 0 & 0 & 0 & 0 \\
\hline Satisfação intrínseca com a tarefa & 0 & - & 0 & 0 & 0 & 0 & 0 \\
\hline Feedback positivo & 0 & 0 & 0 & + & - & 0 & 0 \\
\hline Satisfação geral no trabalho & 0 & 0 & + & + & - & 0 & 0 \\
\hline \multicolumn{8}{|l|}{ Consequências } \\
\hline $\begin{array}{l}\text { Afastamento do emprego por problemas } \\
\text { de saúde }\end{array}$ & + & 0 & 0 & 0 & 0 & 0 & 0 \\
\hline Problemas de saúde & 0 & 0 & 0 & - & 0 & 0 & 0 \\
\hline Pensamento de mudar de profissão & + & 0 & - & 0 & 0 & 0 & 0 \\
\hline
\end{tabular}

Fonte: elaborado pelas autoras.

Nota: + = associação positiva; - = associação negativa; 0 = não associação; as variáveis associadas são apresentadas na direção positiva. 


\section{REFERÊNCIAS}

Aftab, N., Shah, A. A. \& Mehmood, R. (2012). Relationship of self efficacy and burnout among physicians. Academic Research International, 2(2), 539-548.

Andrade, L. V. D. (2012). Mal-estar e atividade docente: um estudo com professoras de educação infantil. Trabalho \& Educação, 21(1), 65-82.

Bakker, A. B. \& Costa, P. L. (2014). Chronic job burnout and daily functioning: a theoretical analysis. Burnout Research, 1(3), 112-119.

Batista, J. B. V., Carlotto, M. S., Coutinho, A. S. \& Augusto, L. G. D. S. (2010). Prevalência da síndrome de burnout e fatores sociodemográficos e laborais em professores de escolas municipais da cidade de João Pessoa, PB. Revista Brasileira de Epidemiologia, 13(3), 502-512.

Bertaci, A. C., Santos, B. B. dos, Coelho, A. T. \& Suda, E. Y. (2011). Síndrome de burnout e nível geral de saúde em professores universitários. Revista Neurobiologia, 74(1), 167-187.

Boa, S. V. D. R. da \& Deps, V. L. (2015). Prevenção e tratamento do estresse e da síndrome de burnout em professores da rede pública de ensino. LinkscienceplaceRevista Cientifica Interdisciplinar, 2(1).

Braun, A. C. \& Carlotto, M. S. (2013). Síndrome de burnout em professores de ensino especial. Barbaroi, 39, 53-69.

Breakwell, G. M. \& Rose, D. (2010). Teoria, método e delineamento de pesquisa. In G. M. Breakwell, C. Fife-Schaw, S. Hammond \& J. A. Smith. (Orgs.), Métodos de pesquisa em Psicologia (3a ed.). (pp. 22-41). Porto Alegre: Artmed.

Byrne, B. M. (1991). Burnout: investigando o impacto das variáveis de base para educadores elementar, intermediário, secundário e universitário. Ensino e Formação de Professores, 7(2), 197-209.

Cabrera, J. H. \& Elvira, J. A. M. (2004). Estrés y burnout en profesores. International journal of clinical and health psychology, 4(3), 597-621.

Carlotto, M. S. (2005). Síndrome de burnout em professores de instituições particulares de ensino. (Tese de Doutorado). Universidade de Santiago de Compostela, Santiago de Compostela.

Carlotto, M. S. (2010). Síndrome de Burnout: diferenças segundo níveis de ensino. Psico, 41(4). 
Carlotto, M. S. (2011). Síndrome de Burnout em professores: prevalência e fatores associados. Psicologia: Teoria e Pesquisa, 27(4), 403-410.

Carlotto, M. S. (2012). Sindrome de Burnout em professores: avaliação, fatores associados e intervenção. Porto: LivPsic.

Carlotto, M. S. \& Câmara, S. G. (2007). Preditores da síndrome de Burnout em professores. Psicologia Escolar e Educacional, 11(1), 101-110.

Carlotto, M. S. \& Câmara, S. G. (2008a). Análise da produção científica sobre a síndrome de Burnout no Brasil. Psico, 39(2).

Carlotto, M. S. \& Câmara, S. G. (2008b). Síndrome de Burnout e estratégias de enfrentamento em professores de escolas públicas e privadas. Psicologia da Educação, 26, 29-46.

Carlotto, M. S., Dias, S. R. D. S., Batista, J. B. V. \& Diehl, L. (2015). O papel mediador da autoeficácia na relação entre a sobrecarga de trabalho e as dimensões de Burnout em professores. Psico-USF, 20(1), 13-23.

Carlotto, M. S., Librelotto, R., Pizzinato, A. \& Barcinski, M. (2012). Prevalência e fatores associados à síndrome de Burnout nos professores de ensino especial. Análise Psicológica, 30(3), 315-327.

Carlotto, M. S. \& Palazzo, L. S. (2006). Síndrome de Burnout e fatores associados: um estudo epidemiológico com professores. Cadernos de Saúde Pública, 22, 1017-1026.

Cebriá-Andreu, J. (2005). El síndrome de desgaste profesional como problema de salud pública. Gaceta Sanitária, 19(6), 470-470.

Cordeiro, A. M., Oliveira, G. M., Rentería, J. M. \& Guimarães, C. A. (2007). Revisão sistemática: uma revisão narrativa. Revista do Colégio Brasileiro de Cirurgiōes, 34(6), 428-431.

Costa, A. B. \& Zoltowski, A. P. C. (2014). Como escrever um artigo de revisão sistemática. In S. H. Koller, M. C. P. P. Couto \& J. V. Hohendorff, Manual de produção cientifica. (pp. 55-70). Porto Alegre: Penso Editora.

Costa, B. E. \& Silva, N. L. (2011). Analysis of environmental factors affecting the quality of teacher's life of public schools from Umuarama. Work (Reading, Mass.), 41, 3693-3700. 
Davis, A. \& Bremmer, G. (2010). O método experimental em Psicologia. In G. M. Breakwell, S. Hammond, C. Fife-Schaw \& J. A. Smith (Eds.), Métodos de pesquisa em Psicologia. (pp. 78-99). Porto Alegre: Artmed.

Droogenbroeck, F. V. \& Spruyt, B. (2015). Do teachers have worse mental health? Review of the existing comparative research and results from the Belgian Health Interview Survey. Teaching and Teacher Education, 51, 88-100.

Fernet, C., Austin, S., Trépanier, S. G. \& Dussault, M. (2013). How do job characteristics contribute to burnout? Exploring the distinct mediating roles of perceived autonomy, competence, and relatedness. European Journal of Work and Organizational Psychology, 22(2), 123-137.

Figueiredo-Ferraz, H., Gil-Monte, P. R., Queirós, C. \& Passos, F. (2014). Factorial validity of the "Spanish Burnout Inventory" among Portuguese Police Officers. Psicologia: Reflexão e Crítica, 27(2), 291-299. Recuperado a partir de http://dx.doi.org/10.1590/1678-7153.201427209

França, H. H. (1987). A síndrome de Burnout. Revista Brasileira de Medicina, 44(8), 197-199.

Galvão, T. F. \& Pereira, M. G. (2014). Revisões sistemáticas da literatura: passos para sua elaboração. Epidemiologia e Serviços de Saúde, 23(1), 183-184.

Garcı a-Olmedo, F., Rodrı guez-Palenzuela, P., Molina, A., Alamillo, J. M., López-Solanilla, E., Berrocal-Lobo, M. \& Poza-Carrión, C. (2001). Antibiotic activities of peptides, hydrogen peroxide and peroxynitrite in plant defence. FEBS letters, 498(2), 219-222.

García-Renedo, M., Llorens, S., Cifre, E. \& Salanova, M. (2006). Antecedentes afectivos de la auto-eficacia docente: un modelo de relaciones estructurales. Revista de Educación, 339, 387-400.

Gasparini, S. M., Barreto, S. M. \& Assunção, A. A. (2005). O professor, as condiçôes de trabalho e os efeitos sobre sua saúde. Educação e Pesquisa, 31(2), 189-199.

Gil-Monte, P. R. (2005). El síndrome de quemarse por el trabajo (burnout). In P. R. Gil-Monte \& B. Moreno-Jiménez, Uma enfermidad laboral en la sociedad del bienestar. (pp. 36-37). Madrid: Pirámide.

Gil-Monte, P. R. (2008). Magnitude of relationship between burnout and absenteeism: a preliminary study. Psychological Reports, 102(2), 465-468. 
Gil-Monte, P. R. (2011). CESQT: Cuestionario para la evaluación del sindrome de quemarse por el trabajo: manual. Madrid: TEA.

Gil-Monte, P. R., Carlotto, M. S. \& Câmara, S. G. (2010). Validação da versão brasileira do "Cuestionario para la evaluación del síndrome de quemarse por el trabajo" em professores. Revista Saúde Pública, 44(1), 140-147.

Gomes, T. M. O. (2015). O relato profissional à luz da metarreflexão: interstícios e confluências no fazer acadêmico-docente. Revista Fundamentos, 2(1).

Gondim, S. M. G., Borges-Andrade, J. E. \& Bastos, A. V. B. (2010). Psicologia do trabalho e das organizaçōes: produção científica e desafios metodológicos. Psicologia em Pesquisa, 4(2), 84-99.

Greenhalgh, T. (1997). How to read a paper: papers that summarise other papers (systematic reviews and meta-analyses). Bmj, 315(7109), 672-675.

Guglielmi, R. S. \& Tatrow, K. (1998). Ocupational stress, burnout, and health in teachers: a methodological and theoretical analysis. Review of Education Research, 68(1), 61-69.

Kahhale, E. M. P. (2003). Psicologia na saúde: em busca de uma leitura crítica e de uma atuação compromissada. In A. M. B. Bock (Org.), A perspectiva sóciohistórica na formação em Psicologia. (pp. 161-191). Petrópolis: Vozes.

Kristensen, T. S., Borritz, M., Villadsen, E. \& Christensen, K. B. (2005). The Copenhagen Burnout Inventory: a new tool for the assessment of burnout. Work \& Stress, 19(3), 192-207.

Leiter, M. P. \& Maslach, C. (2014). Interventions to prevent and alleviate burnout. In M. P. Leiter, A. B. Bakker \& C. Maslach (Eds.), Burnout at work: a psychological perspective. (pp. 145-167). Hove: Psychology Press.

Lopes, A. P. \& Pontes, E. A. S. (2009). Síndrome de Burnout: um estudo comparativo entre professores das redes pública estadual e particular. Psicologia Escolar e Educacional, 13(2), 275-281.

Maslach, C. \& Jackson, S. E. (1981). The measurement of experienced burnout. Journal of Organizational Behavior, 2(2), 99-113.

Maslach, C. \& Leiter, M. P. (1997). The truth about burnout: how organization cause, personal stress and what to do about it. San Francisco: Jossey-Bass. 
Maslach, C., Schaufeli, W. B. \& Leiter, M. P. (2001). Job burnout. Annual Review of Psychology, 52(1), 397-422. Recuperado a partir de http://doi: 10.1146/annurev.psych.52.1.397.

Mazon, V., Carlotto, M. S. \& Câmara, S. (2008). Síndrome de Burnout e estratégias de enfrentamento em professores. Arquivos Brasileiros de Psicologia, 60(1), 55-66.

Moher, D., Liberati, A., Tetzlaff, J., Altman, D. G. \& Prisma Group. (2010). Preferred reporting items for systematic reviews and meta-analyses: the Prisma statement. International Journal of Surgery, 8(5), 336-341.

Moreira, H. D. R., Farias, G. O., Both, J. \& Nascimento, J. V. D. (2012). Qualidade de vida no trabalho e síndrome de Burnout em professores de Educação Física do Estado do Rio Grande do Sul, Brasil. Revista Brasileira de Atividade Fisica \& Saúde, 14(2), 115-122.

Mota, M. M. P. E. D. (2010). Metodologia de pesquisa em desenvolvimento humano: velhas questões revisitadas. Psicologia em Pesquisa, 4(2), 144-149.

Naghieh, A., Montgomery, P., Bonell, C. P., Thompson, M. \& Aber, J. L. (2015). Organisational interventions for improving wellbeing and reducing work related stress in teachers. Cochrane Database of Systematic Reviews, 1. Recuperado a partir de http://onlinelibrary.wiley.com/wol1/doi/10.1002/14651858. CD010306.pub2/full

Nogueira, I. M. G. D. M. (2012). Clima de escola. (Dissertação de Mestrado). Universidade Fernando Pessoa, Porto.

Palmer, Y., Gomez-Vera, A., Cabrera-Pivaral, C., Prince-Vélez, R. \& Searcy, R. (2005). Factores de riesgo organizacionales asociados al síndrome de Burnout en médicos anestesiólogos. Salud Mental, 28(1), 82-91.

Peeters, M. A. \& Ruttel, C. G. (2005). Time management behavior as a moderator for the job demand-control interaction. Journal of Occupational Health Psychology, 10(1), 64-75.

Pocinho, M. (2008). Liçôes de metanálise: um trabalho de compilação. (Anotações dos cursos do site www.cochrane.org/cochrane/workshop.htm. São Paulo.

Rodrigues, C. D., Chaves, L. B. \& Carlotto, M. S. (2010). Síndrome de Burnout em professores de educação pré-escolar. Interação em Psicologia, 14(2), 197 204. 
Salanova, M. \& Llorens, S. (2008). Estado actual y retos futuros em el estúdio del burnout. Papeles del Psicólogo, 29(1), 59-67.

Sampaio, R. F. \& Mancini, M. C. (2007). Estudos de revisão sistemática: um guia para síntese criteriosa da evidência científica. Brazilian Journal of Physical Therapy, 11(1), 83-89.

Santana, A., Marchi, D., Junior, L. C., Girondoli, Y. M. \& Chiappeta, A. (2011). Burnout syndrome, working conditions, and health: a reality among public high school teachers in Brazil. Work (Reading, Mass.), 41, 3709-3717.

Santos, A. A. D. \& Nascimento Sobrinho, C. L. (2012). Revisão sistemática da prevalência da síndrome de Burnout em professores do ensino fundamental e médio. Revista Baiana de Saúde Pública, 35(2), 299.

Schaufeli, W. B., Maslach, C. \& Marek, T. (1993). Professional burnout: recent developments in theory and research. Washington: Taylor \& Francis.

Silva, F. M., Silva, N. A. \& Martini, C. M. (2013). Síndrome de Burnout em professores da Escola Polo José de Anchieta e da Escola Estadual Cora Coralina na cidade de Ariquemes. Revista Fiar: Revista do Núcleo de Pesquisa e Extensão Ariquemes, 2(1), 187-202.

Silva, G. N. da. \& Carlotto, M. S. (2003). Síndrome de Burnout: um estudo com professores da rede pública. Abrapee, 7(2), 145-153.

Silva, J. L. L., Dias, A. C. \& Teixeira, L. R. (2012). Discussão sobre as causas da síndrome de Burnout e suas implicações à saúde do profissional de enfermagem. Aquichán, 12(2), 144-59.

Silva, P. C. D. \& Merlo, Á. R. C. (2007). Pleasure and suffering of psychologists who work in private companies. Psicologia: Ciência e Profissão, 27(1), 132-147.

Suda, E. Y., Coelho, A. T., Bertaci, A. C. \& Santos, B. B. D. (2011). Relação entre nível geral de saúde, dor musculoesquelética e síndrome de Burnout em professores universitários. Fisioterapia e Pesquisa, 18(3), 270-274.

Taris, T. W. \& Kompier, M. A. (2014). Cause and effect: optimizing the designs of longitudinal studies in occupational health psychology. Work \& Stress, 28, $1-8$.

Tibúrcio, A. \& Moreno, C. R. C. (2009). Síndrome de Burnout em professores do ensino médio de escolas pertencentes à Gerência Regional de Educação e 
Inovação (Gerei) do Município de Tubarão (SC). Revista de Gestão Integrada em Saúde do Trabalho e Meio Ambiente, 4(1), 1/3-14.

Truchot, D., Keirsebilck, L. \& Meyer, S. (2000) Communal orientation may not buffer burnout. Psychological Reports, 86(3), 872-878. 